\title{
Description of Lutzomyia velezi, a new species of phlebotomine sand fly (Diptera: Psychodidae) from the Department of Antioquia, Colombia
}

\author{
Eduar Elías Bejarano ${ }^{1 /}$, Rafael José Vivero², Sandra Uribe ${ }^{3}$ \\ ${ }^{1}$ Grupo de Investigaciones Biomédicas, Universidad de Sucre, Cra. 14 16-B-32, AA 406 Sincelejo, Colombia \\ ${ }^{2}$ Programa de Estudio y Control de Enfermedades Tropicales, Universidad de Antioquia, Medellín, Colombia \\ ${ }^{3}$ Grupo de Sistemática Molecular, Universidad Nacional de Colombia, Medellín, Colombia
}

The phlebotomine sand fly Lutzomyia velezi sp.nov. was described and illustrated from male specimens collected by light trap in the Reserva Natural Cañon del Río Claro in the Central Cordillera of the Colombian Andes. The new species belongs to the series sanguinaria of the subgenus Helcocyrtomyia, which is represented in Colombia by Lutzomyia cirrita, Lutzomyia hartmanni, Lutzomyia sanguinaria, Lutzomyia scorzai, Lutzomyia sp. of Pichindé and Lutzomyia tortura. The new species can be differentiated from others of the subgenus by the combination of the following characteristics: long antennal ascoids, reaching level of the papilla, coxite with a single basal seta and fifth palpomere longer than or equal to the sum of the lengths of the third and fourth palpomeres.

Key words: Lutzomyia velezi sp.nov. - Helcocyrtomyia - Phlebotominae - Colombia - sand fly

The subgenus Helcocyrtomyia Barretto, 1962 is a group of neotropical phlebotomine sand flies placed within the genus Lutzomyia França, 1924 both in the widely used key of Young and Duncan (1994) and in the recent taxonomic proposal of Galati (2003). According to Galati and Cáceres (1994), the subgenus is comprised of three series of species, i.e., sanguinaria Barretto, 1962, osornoi Galati \& Cáceres, 1994 and peruensis Barretto, 1962. Species of the series sanguinar$i a$ are characterised by the presence of relatively short 4th and 5th palpomeres, those of the series osornoi by having only the 4th palpomere reduced and those of the series peruensis by having the lateral lobes longer than the coxite. In members of the two latter series, there is also a marked prolongation of the head and clypeus, as well as an increase in the number of setae on the coxite (Galati \& Cáceres 1994).

To date, 35 Lutzomyia species belonging to the subgenus Helcocyrtomyia have been discovered. The majority of these species come from the mountainous zones of Colombia, Venezuela, Ecuador, Bolivia and Peru, particularly from the latter nation, where the group exhibits its greatest diversity (Galati 2003). In Colombia, the subgenus is represented by Lutzomyia ceferinoi (Ortiz \& Alvarez, 1963), Lutzomyia cirrita Young \& Porter, 1974, Lutzomyia erwindonaldoi (Ortiz, 1978), Lutzomyia osornoi (Ristorcelli \& Van Ty, 1941), Lutzomyia sanguinaria

\footnotetext{
Financial support: Pecet, Universidad de Antioquia

+ Corresponding author: eduarelias@yahoo.com

Received 19 October 2009

Accepted 26 March 2010
}

(Fairchild \& Hertig, 1957), Lutzomyia scorzai (Ortiz, 1965), Lutzomyia sp. of Pichindé Young, 1979, Lutzomyia strictivilla Young, 1979, Lutzomyia tortura Young \& Rogers, 1984 and Lutzomyia hartmanni (Fairchild \& Hertig, 1957) (Bejarano 2006), the last of which is incriminated as the vector of Leishmania colombiensis Kreutzer et al. 1991 in Colombia (Kreutzer et al. 1991).

In this paper, a new species of Lutzomyia of the subgenus Helcocyrtomyia found in the Central Cordillera of the Colombian Andes was described and illustrated.

\section{MATERIALS AND METHODS}

Phlebotomine sand flies were collected in the Reserva Natural Cañón del Río Claro "El Refugio" (553’N $74^{\circ} 51^{\prime} \mathrm{W}$ ) in the municipality of San Francisco, Department of Antioquia, Colombia. This reserve is situated on the SE slope of the Central Cordillera of the Andes, considered to be one of the probable Pleistocene refuges in Colombia. The area is classified ecologically as humid tropical forest (Holdridge 1967), with a mean annual temperature of approximately $24^{\circ} \mathrm{C}$ and a relative humidity of $80-85 \%$.

The type material was collected from 18-6 h using a Communicable Disease Center (CDC) light trap hung over a path at 320 masl. Phlebotomine sand flies were cleared in lactophenol (a 1:1 mixture of lactic acid and phenol) for $24 \mathrm{~h}$ and mounted on microscope slides in Canada balsam. Morphometric estimates of the characteristics of taxonomic interest were carried out with an eyepiece micrometer on a Carl Zeiss Primo Star microscope previously calibrated with a $5+100 / 100$ $\mathrm{mm}$ Stemi eyepiece micrometre. The type material was deposited in the Colección de Vectores y Hospedadores Intermediarios de Enfermedades Tropicales (VHET) of Programa de Estudio y Control de Enfermedades Tropicales (PECET) in the University of Antioquia in Medellín, Colombia. 
Lutzomyia velezi Bejarano, Vivero \& Uribe, sp.nov. (Figs 1-4)

Large phlebotomine sand fly, length approximately $3.250 \mu \mathrm{m}$ from the labro-epipharynx to the genitalia.

Male: head - Colour brown, with proboscis, palps and antennae paler. Vertex without midline and with several rows of large setal scars converging towards the centre. Length of head from vertex to point of clypeus $430 \mu \mathrm{m}$, width $410 \mu \mathrm{m}$. Eyes large, $250 \mu \mathrm{m}$ long by $170 \mu \mathrm{m}$ wide. Interocular distance $78 \mu \mathrm{m}$, equivalent to the diameter of 3.7 facets. Interocular suture incomplete. Clypeus $113 \mu \mathrm{m}$ long, bearing 26 large setal scars. Length of labro-epipharynx $235 \mu \mathrm{m}$. Labial sutures forming a furca. Flagellomere lengths in micrometers: I 363, II 138, III 135, IV 135, V 130, VI 123, VII 120 and VIII 115, other antennal segments absent. Flagellomere I longer than labro-epipharynx, reaching distal extremity of third palpomere. Papillae on flagellomeres I-III, those of flagellomere II inserted on the basal proportion 0.20 of the internal face of the segment. Ascoids paired, long and simple, not passing apex of each segment. Flagellomere II with internal and external ascoids implanted at same level, both reaching level of the papilla. Length of palpomeres in micrometers: P1 35, P2 120, P3 153, P4 80 and P5 238 in the ratio 1.0:3.4:4.4:2.3:6.8. Palpal formula 1.4.2.3.5. Newstead's spines of apex not dilated, covering the internal surface of the third palpal segment. Third palpomere with a spiniform seta near apex. Fourth palpomere with two pairs of spiniform setae. Fifth palpomere with six spiniform setae, three of them apical. Pharynx slightly widened close to apex, with some groove from basal proportion 0.78 downwards. Length of pharynx $210 \mu \mathrm{m}$, maximum width $52 \mu \mathrm{m}$. Cibarium without teeth. Pigmented area very faint. Cibarial arch incomplete, discernible only at sides. Thorax - Scutum and scutellum brown, with coxae and parts of pleura paler. Pleura with 14 superior and 4 inferior anepisternal setae. Ventrocervical sensilla not discernible. Length of wing from base of costal vein $2.134 \mu \mathrm{m}$, maximum width $610 \mu \mathrm{m}$. Ratio of length/maximum width of wing 3.5. Lengths of principal wing veins: $R_{2}(\alpha) 645 \mu \mathrm{m}, R_{2+3}$ (ß) $200 \mu \mathrm{m}, \mathrm{R}_{2+3+4}(\gamma) 170 \mu \mathrm{m}, \mathrm{R}_{3}(\varepsilon) 770 \mu \mathrm{m}, \mathrm{R}_{4}(\theta) 960$ $\mu \mathrm{m}$ and $\mathrm{R}_{5} 1.219 \mu \mathrm{m}$. Length from bifurcation $\mathrm{R}_{2+3}$ to termination $\mathrm{R}_{1}(\delta) 260 \mu \mathrm{m}$, distance from bifurcation $\mathrm{R}_{2+3+4}$ to bifurcation $\mathrm{M}_{1+2}(\pi) 102 \mu \mathrm{m}$. Both $\delta$ and $\pi$-positive. Veins R1 and M2 slightly sclerotised. Vein Sc straight, without reaching costal and $R_{1}$ veins. Transverse vein $\mathrm{r}-\mathrm{m}$ absent. Halteres with maximum width $97 \mu \mathrm{m}$, length $374 \mu \mathrm{m}$. Ratio between length of haltere and its maximum width 3.86. Third tarsomere with spines implanted in four levels, in paratype. Abdomen - Abdomen length $2.120 \mu \mathrm{m}$, including genitalia. Coxite length $310 \mu \mathrm{m}$, maximum width $85 \mu \mathrm{m}$. Base of coxite with single persistent seta, slightly shorter than width of coxite. Length of gonostyle $180 \mu \mathrm{m}$, maximum width $43 \mu \mathrm{m}$. Style with five spines, arranged 2.1.1.1, with two apical spines implanted at same level, one upper external spine in basal proportion 0.77 , one lower external spine in basal proportion 0.54 and an internal spine in basal proportion 0.49. Paramere simple, with widened base, slender apex and straight dorsum. Paramere length 183 $\mu \mathrm{m}$, covered with relatively long setae and with some fine longitudinal grooves. Lateral lobe $240 \mu \mathrm{m}$ long, extending further than tip of paramere but not passing apex of coxite. Aedeagus conical, slender and pigmented. Length of genital pump $104 \mu \mathrm{m}$, including ejaculatory apodeme, length of genital filaments 386 $\mu \mathrm{m}$. Ratio between length of genital filaments and genital pump 3.7. Ejaculatory apodeme base not widened. Genital filaments thin not modified at tips.

Type data - Holotype male - Reserva Natural Cañón del Río Claro "El Refugio", San Francisco, Antioquia, CAB, 25-V-2008, CDC light trap, R. Vivero, S. Uribe coll., VHET. Paratypes: two males, same data as holotype, except 26-V-2008.

Etymology - The new species is dedicated to Prof. Dr. Iván Darío Vélez Bernal, founder and director of PECET of the Universidad de Antioquia, in recognition for his contribution to the eco-epidemiology of leishmaniasis in Colombia.

Taxonomic discussion - The presence of a single seta at the base of the coxite, short lateral lobes and small clypeus allows $L$. velezi sp.nov. to be included in the series sanguinaria of the subgenus Helcocyrtomyia. The species of the series sanguinaria known by both the sexes comprise Lutzomyia adamsi, L. cirrita, Lutzomyia gonzaloi Ogusuku, Canales \& Pérez, 1997, Lutzomyia guderiani Torres-Espejo, Cáceres \& Le Pont, 1995, L. hartmanni, Lutzomyia kirigetiensis Galati \& Cáceres, 1992, Lutzomyia monzonensis Ogusuku, Canales \& Pérez, 1997, L. sanguinaria, L. scorzai, L. sp. of Pichindé and L. tortura. Lutzomyia caceresi Le Pont, Matias, Martínez \& Dujardin, 2004 is known from males only and Lutzomyia botella is known from females.

The male of $L$. velezi sp.nov. is easily differentiated from the previous species by having long antennal ascoids, which extend to the level of the papilla. In the other members of the series sanguinaria, the ascoids are relatively short, reaching the centre of the flagellomere in some species but never reaching the level of the papilla. The single seta at the base of the coxite also allows $L$. velezi $\mathrm{sp}$. nov. to be distinguished from $L$. hartmanni, $L$. sanguinaria, L. scorzai, L. sp. de Pichindé, L. kirigetiensis, L. gonzaloi and L. monzonensis, which possess from 2-6 persistent setae. The same feature separates the new species from $L$. tortura and $L$. adamsi, which lack setae on the coxite and $L$. cirrita, which presents numerous setae dispersed over half of the structure. With relation to L. guderiani, which can have one or two fine setae on the coxite, $L$. velezi sp.nov. is also distinguished by the length of the labro-epipharynx, which, in the former, measures 313-360 $\mu \mathrm{m}$ (Torres-Espejo et al. 1995).

The closest species to $L$. velezi sp.nov. morphologically is L. caceresi of Bolivia (Le Pont et al. 2004), which can be differentiated by the length of the antennal ascoids and palps. L. caceresi has short antennal ascoids, covering one-fourth of the length of flagellomere 


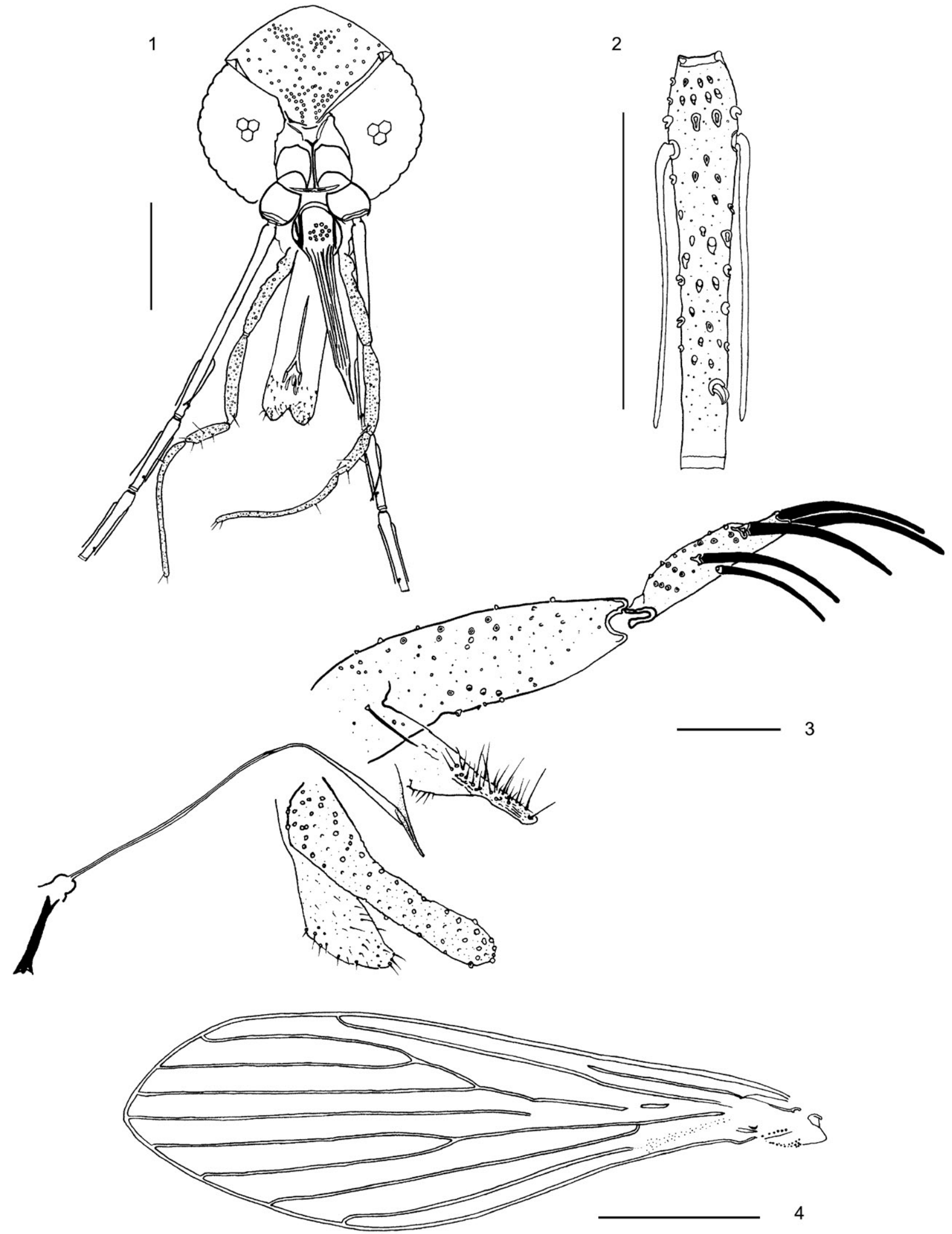

Figs 1-4: Lutzomyia velezi Bejarano, Vivero \& Uribe, sp.nov. 1: head (paratype), Bar $=200 \mu \mathrm{m}$; 2: flagellomere II (holotype), Bar $=100 \mu \mathrm{m}$; 3: terminalia, genital pump and filaments (holotype), $B a r=100 \mu \mathrm{m} ; 4$ : wing (holotype), $\operatorname{Bar}=500 \mu \mathrm{m}$. 
II and not reaching the level of the papilla, while in $L$. velezi sp.nov., the ascoids cover more than two-thirds of the antennal segment and reach the level of the papilla. With respect to the palps, in L. caceresi, the length of the 5th palpomere is much less than the sum of the lengths of the two preceding segments, while in $L$. velezi sp.nov., the 5th palpomere is longer or equivalent to the sum of the lengths of the 3rd and 4rth papal segments.

Together with the type material of $L$. velezi sp.nov., a female, the general characteristics of which, such as head, palpomeres, flagellomeres, cibarial armature, spermathecae and third tarsomere, are consistent with those of most species of the series sanguinaria, was captured; however, its spermatheca is very different from that of $L$. sanguinaria and L. botella. Although we considered the single female collected to be conspecific with L. velezi sp.nov., it was not in sufficiently good condition to warrant formal description.

The description of $L$. velezi sp.nov. increases the number of Lutzomyia species recorded in Colombia to 152 , making it the country with the greatest diversity of phlebotomine sand flies after Brazil. This highlights the need to increase our knowledge of the epidemiological role of this group of insects in Colombia.

\section{ACKNOWLEDGEMENTS}

To the reviewers's thoughtful and constructive comments, which helped to improve the paper.

\section{REFERENCES}

Bejarano EE 2006. Lista actualizada de los psicódidos (Diptera: Psychodidae) de Colombia. Folia Entomol Mex 45: 47-56.

Galati EAB 2003. Classificação de Phlebotominae. In EF Rangel, R Lainson R (eds.), Flebotomíneos do Brasil, Fiocruz, Rio de Janeiro, p. 23-51.

Galati EAB, Cáceres AG 1994. Descrição de Lutzomyia pallidithorax, sp. n. e de Lutzomyia castanea, sp. n. do Peru e análise cladística das séries do subgênero Helcocyrtomyia Barretto (Diptera: Psychodidae). Rev Bras Entomol 38: 471-488.

Holdridge LR 1967. Life zone ecology, Tropical Science Center, San José, 206 pp.

Kreutzer RD, Corredor A, Grimaldi G Jr, Grogl M, Rowton ED, Young DG, Morales A, McMahon-Pratt D, Guzman H, Tesh RB 1991. Characterization of Leishmania colombiensis sp. n (Kinetoplastida: Trypanosomatidae), a new parasite infecting humans, animals and phlebotomine sand flies in Colombia and Panama. Am J Trop Med Hyg 44: 662-675.

Le Pont F, Matias A, Martinez E, Dujardin JP 2004. Phébotomes de Bolivie: description de quatre nouvelles espèces de Lutzomyia (Diptera: Psychodidae). Bull Soc Entom Fr 109: 145-154.

Torres-Espejo JM, Caceres GA, Le Pont F 1995. Description de deux nouvelles espèces de phlébotomes du sous-genre Helcocyrtomyia, du Piémont andin bolivien (Diptera: Psychodidae). Parasite 2: 157-162.

Young DG, Duncan MA 1994. Guide to the identification and geographic distribution of Lutzomyia sand flies in Mexico, the West Indies, Central and South America (Diptera: Psychodidae). Mem Am Entomol Inst 54: 1-881. 